\title{
USING VOICE RECOGNITION IN E-LEARNING SYSTEM TO REDUCE EDUCATIONAL INEQUALITY DURING COVID-19
}

\author{
Vladimir Tregubov \\ Department of Business and Logistics, Yuri Gagarin State Technical University of \\ Saratov, Saratov, Russia
}

\begin{abstract}
During the COVID -19 pandemic, educational institutions around the world faced problems that have to do with the frustration of students for whom traditional education has been replaced by the online format. Students are experiencing technical difficulties in the digitalization of education. International monitoring of education systems has shown that quite a few countries were ready to move to distance learning, both for technical and economic reasons. The covid pandemic has caused an increase in educational inequality. Elearning systems were expected to reduce inequality in education, but empirical research has shown that learning in this format not only does not reduce, but can increase inequality, increasing the gap in educational outcomes between students with different socioeconomic status. The article describes applications of using voice recognition technology based on artificial intelligence which, by our opinion, may reduce educational inequality during covid-19. We presented a comparative analysis of existing examples artificial intelligence in the educational process. Artificial intelligence uses in specialized software it makes educational process more convenient for both the students and the teachers. There is a description of an application "Academic phrase bank" developed by author. The application consists of two specialising actions for Google assistant. The application allows to increase academic vocabulary, train of creating grammatically correct academic expressions, and memorize templates of academic phrases. In active mode, this application helps to create correct phrases of academic English and improve the abilities of understanding English speech.
\end{abstract}

\section{KEYWORDS}

Academic English, COVID-19, personal assistant, academic publications, applications for learning English

\section{INTRODUCTION}

The coronavirus pandemic has led to the temporary closure of educational institutions and switch to online learning around the world, which has negatively impacted education in many countries. A review by the World Bank shows that the current situation requires special actions aimed at developing new methods and approaches to the organization of the educational process. On the other hand, experts note that the coronavirus pandemic has only highlighted existing problems in educational systems due to economic stratification. For example, even before the pandemic, nearly 300 million schoolchildren in low-income countries did not attend school, many of them received poor quality education, and more than half of 10-year-olds in such countries could not read and could not understand texts appropriate for their age [1].

There are two key factors that, according to World Bank experts, threaten the stagnation of education in the world during the coronavirus pandemic. The first is the closure of educational institutions and mass transition to online learning. The second is the economic downturn that will 
inevitably follow the coronavirus pandemic, which will reduce the availability of education for most of the population.

Around the world, COVID-19 quarantine has caused a boom in distance learning [2]. Now, there are many eLearning platforms that have multiplied their activity and attendance. Distance learning technologies minimize the damage caused by school and university closures. Researchers noted that modern technologies of distance learning, especially with artificial intelligence, have been actively developed [3]. For example, the University of South Wales developed a special training platform that uses Microsoft Teams technology. Using of this platform allows students to study around the clock and they can easily obtain necessary information. This allows not to decrease the motivation of students and as a result the university was able to significantly reduce the percentage of students who drop out [4].

International monitoring of education systems has shown that quite a few countries were ready to move to distance learning, both for technical and economic reasons. Among the difficulties of the introduction of distance learning, psychological (reducing the effectiveness of training because of the unfamiliar format of classes and drop in motivation), social and psychological (family responsibility for the organization of distance learning students), methodological (difficulty in transferring some activities into the online environment, additional training of teachers in new teaching methods), political (lack of management models that describe the transition to online learning).

A general idea of the education system in the context of the COVID-19 pandemic is provided not only by documents of international organizations published following the results of monitoring, but also by materials of academic research on the problems of education in the pandemic period. Extensive monitoring of education conducted by international organizations and scientific research focused on specific problems seem to be complementary strategies to recreate the context of the functioning of educational systems in the context of a pandemic.

Even before the COVID-19 pandemic, online technologies were among the priorities for the development of university education in different countries - Vietnam, Germany, India, Canada, China, Russia, the USA, Turkey, but the urgent nature of changes and forced digitalization have placed online education on the first place among the crucial problems. The sample of scientific publications for the review was formed by the keywords: education COVID, education pandemic, university COVID, university pandemic, school COVID, school pandemic.

The pandemic has highlighted two trends in the education of different countries: the disruption of the educational process and the forced transition to distance learning. Disruption of the educational process has led to an increase in socioeconomic inequality among students. International organizations cite interrupted schooling, difficulty in obtaining customary economic support (e.g., reduced meals at schools), abandonment (for working parents) or high economic costs for families (childcare requires a parent to quit working outside the home), increased pressure on the healthcare system (female workers must stay home to look after children).

Research on online education in universities during the coronavirus pandemic is devoted to:

- the frustrations of students who have had their offline education replaced by an online format, whose expectations do not come true and who are experiencing technical difficulties in the conditions of digitalization of education [5].

- methodological and technological support for online learning in the context of urgent transition to distance learning [6]. 
- lack of methodological support for online programs that can develop critical thinking, as well as the need for state support for the transition to quality online learning [7].

- the consequences of forced digitalization and the forced total shift of universities to online learning [8].

- digital technologies in education and the need for social mobilization to promote online learning [9].

- creation of mechanisms to integrate online and offline learning after the pandemic [10].

- post-pandemic changes in the content of educational programs; thus, in connection with today's "digital transformation" of the legal profession, the possibility of strengthening the digitalization of education is being considered [9].

COVID-19 becomes an unprecedented technological development of universities in such circumstances. The study of the consequences of the forced and urgent transition to online learning during the pandemic has intensified not only experimental or empirical research, but also research for an adequate theoretical framework for making sense of the new reality. In developing countries (e.g., the Republic of Guyana), the lack of computers, the Internet, and even electricity completely blocks the educational process, especially in rural areas [11]. Using television as an alternative to "inaccessible online education," according to research, equalizes access to educational products in distance learning. In Los Angeles, schools have partnered with local PBS stations, allowing students to receive documentaries and educational programming via television.

Comparison of management practices in adapting universities to online learning is particularly optimistic in assessing volunteer participation in the organization of online interaction between educators and students. The digitalization of university education based on advanced technologies, such as multimodal learning technology, virtual reality, augmented reality, the Internet of Things, etc.

For example, Murphy, reflecting on post-pandemic pedagogy, pay attention to the rhetoric accompanying the urgent transition to online learning: the non-digital format of education seems unsafe in a pandemic. He suggested using securitization theory to analyze the post-pandemic situation in educational institutions. Burns offers to rethink the role of ethics in post-pandemic pedagogy, rejecting the COVID-induced neoliberal transformation of education by choosing to guide the practice of caring and compassion. In pandemic settings, researchers present students from low-income families as the most vulnerable groups in terms of access to education [12], children from migrant families, and students with disabilities [13], just as in normal settings.

Are high school graduates themselves aware of the deterioration of their educational outcomes during the coronavirus pandemic? Students who studied at universities during the quarantine period are not only aware, but also reveal in sociological surveys a list of their defeats. According to the research, $13 \%$ of U.S. students believe they have left school because of the COVID-19 pandemic, $40 \%$ have lost a job, internship or job offer, and 29\% expect to earn less at age 35 than today's young professionals who were educated before the pandemic [12].

One factor in the reproduction of inequality in education has been the "lifestyle trauma" inflicted on society by the COVID-19 pandemic. A study conducted in Russia showed that graduates of general education schools in 2020 adjusted their educational mobility strategies in favor of "local universities" [14]. The authors of the article explained the increased attractiveness of regional universities (the number of state-funded places in them has increased) as a reason, but they believe that the coronavirus epidemic is also significant: the threat of infection has dramatically increased the value of safety for school graduates. 
Thus, the rejection of educational mobility from the regions to the center because of "lifestyle trauma" by the circumstances of the coronavirus epidemic can be seen in the context of the reproduction of inequality in education. Pandemic educational disruptions affect not only students and faculty, but also the state of universities. The financial constraints caused by the pandemic block university activity in various areas, for example, social aid to students and scholarships, faculty development, etc. The most vulnerable groups, such as international students in a pandemic are need of additional assistance from the host educational institutions. University research has also declined, mainly due to underfunding and demands for social isolation [15].

Social isolation makes it difficult for research institutions, especially laboratories and field units, to operate, causing significant damage to research projects. Recruitment of foreign personnel and exchange of qualified researchers have been suspended due to travel restrictions. Furthermore, after a pandemic, universities and their sponsors are likely to be in financial difficulty, and projects not related to COVID will be underestimated and underfunded. Researchers argue for state support for universities because the pandemic destroys mechanisms to promote student mobility and the internationalization of the student community, which weakens the position of national universities in international rankings [16].

\section{EDUCATIONAL INEQUALITY}

The covid pandemic has caused an increase in educational inequality. Massive open online courses and eLearning systems were expected to reduce inequality in education, but empirical research has shown that learning in this format not only does not reduce, but can increase inequality, increasing the gap in educational outcomes between students with different socioeconomic status [17]. In the face of the pandemic, the mass shift to distance learning was the only way to continue the learning process, with the risks of increasing inequality and in different dimensions of inequality.

The first expression of inequality is associated with limitations on access to high-speed Internet and the availability of necessary computer equipment. In Russia, according to research, Internet coverage among young people under 30 years of age reached $99 \%$ in 2018 . However, this does not mean that there are no technical problems in teaching. First, there is a large proportion of young people who use the mobile Internet, and the growth of Internet coverage is related to the growing number of students in this segment. Among young people, $41 \%$ of users access the Internet from mobile devices, which are not suitable for effective learning. Second, the speed of the Internet, its cost, and penetration significantly vary in different regions of Russia. Research shows that access to the Internet and various technical means (computers, laptops, etc.) is unequal in groups that differ by type of settlement and income. The second expression of inequality is individual differences in the usage of the Internet, and people, even having the same technical capabilities of access to the Internet, have got different results.

With the widespread introduction of the Internet, people use it differently: those with a higher level of education - for training and career advancement, lower - for entertainment [18]. Differences are observed not only in human behavior on the Internet, but even when using the same Web sites. The transition to a distance format has required students, as well as faculty and other staff, to familiarize themselves with new platforms of interaction and a new level of digital literacy.

Students born between 1980 and 1994 are often described as "net generation" or "digital native" because of their early awareness to computer technology [19]. However, research shows that young people's knowledge of technology is often limited to simple operations: searching for information on the Internet, writing letters, using basic programs [20]. Respondents with prominent levels of technology proficiency have significantly fewer barriers to communication on an online platform, 
and they are easier to deal with administrative and technical problems [21]. At the same time, many of today's freshman have poor computer literacy, despite the widespread belief that they should be proficient in computer. Distance learning requires specific skills, experience and knowledge, in particular the ability to independently maintain the necessary level of motivation and build their learning strategy [22], developed critical thinking skills [23], and experience in learning in this.

The studies note significant variation in the extent of the difficulties that students experience in the transition to distance learning, depending on the level and year of study and the specialty. Among the most vulnerable groups are freshmen, undergraduate students, and science, engineering, and art and design students. In addition, the experience and evaluation of the distance learning experience differed significantly depending on the socio-economic status of respondents. Furthermore, a significant association was found between the severity of depression symptoms and family income levels [24]. A study at a major US research university found that low-income students were more likely to expect to have to postpone graduation because of a pandemic [12].

\section{USING AI TO REDUCE EDUCATIONAL INEQUALITY}

Active development of artificial intelligence (AI) leads to the fact that AI is widely spread in various fields, including education and AI can help to reduce educational inequality [25]. We use the term "artificial intelligence" in the narrow meaning as a specialized software system for implementation a natural user interface. An educational platform with AI can be adjusted to meet the needs of students and consider their personal features (initial level of knowledge, speed of learning, current interests) for identifying the most effective way of studying for them. The interaction students with a smart platform reveal the weaknesses of students and motivate them for additional studying, so it makes possible to create a system of adaptive learning [26].

There are some AI-based technologies popular in the educational process [27]: adaptive knowledge assessment, spaced repetition, virtual assistants, adaptive feedback, formal verification of creative works. Let us briefly consider the features of these technologies and the mechanisms of their implementation with AI.

Computer-aided assessment with AI [28] implies using of specialized applications that allow to test, and automatic check various types of creative work, such as essays, etc. System with computer-aided assessment analyze answers of students, providing feedback, finding factual or semantic errors. The data gathered from student' answers are using for preparation an individual learning path adapted to the current knowledge of students.

The spaced repetition technique based on the theory that a proper time interval of information representation allows maximizing the rate of learning [29]. AI technology in spaced repetition software applications allows recording and tracking progress, when the information was presented, how effective it was for a particular learner, and then to adapt the time intervals of the information representation when it is most appropriate for the learner.

Traditional educational system uses different types of feedback, such as checking and evaluation of student's work, interaction tests, different teacher's activities. Artificial intelligence makes it possible to create specialized chatbots, which can interact with the student through a dialogue interface, analyze their responses, and provide quality feedback to make easier the teacher's work. In the future, these chatbots will be transformed into virtual assistants and be able to respond to students' requests more accurately and quickly in the natural language [30]. 
The technology of virtual assistants (VAS) is a perspective variant of the AI implementation [31]. One of the first in the mid-nineties, Microsoft has released the office assistant "Clippie", a specialized virtual assistant, which should help users to effectively use Microsoft Office. This feature got many negative responses from users, so in later versions of Microsoft Office, this assistant was removed because it showed low efficiency and negative attitude of users.

The surge in popularity of virtual assistants has been observed over the last few years, and they are especially widely used in modern smartphones. Many software companies like Amazon, Google, Microsoft have released their own virtual assistants [32]. The growing interest to this topic related to dramatically improvement of natural speech recognition, which allows to implement an effective voice interface [33]. A significant increasing of the usefulness of virtual assistants also correlated with the development of the Internet of things (IoT).

Virtual assistants allow to manage IoT devices, organize and analyze information obtained from both virtual and physical sources. Modern personal assistants use AI extensively for automation tasks of everyday activities, such as creation of reminders, prompting required information in the current context, constructing routes, grammar checking, translating, etc.

There is a particular interest in using AI for adaptive learning [34]. Adaptive learning is an educational method of using modern computer algorithms to teach students in accordance with their individual characteristics. Adaptive learning is considered: the emotional state of a student, his ability to perceive different types of information, the current level of learning skills, gender, etc. Adaptation is that the curriculum customized to the student, try to build an individual learning trajectory.

In many countries, the adaptive learning based on AI is being actively implemented with supporting of the government. There are a few countries where it is enshrined as a legal framework. In Brazil, for example, the Geekie system [35]. This system allows pupils to prepare for the final examination at school. At the beginning of the training, a student takes some tests and selects the own learning goal, then the system with AI analyses the student's preferences, prepares individual learning trajectories for them, highlights the necessary and suitable content. In learning, a specialized program captures every student's action and transmits information to the system. Each student can have a personal pace of learning and the system accumulates information about students and adapts the learning process to their abilities. The developer points out that the using of this system has increased results of the final exams for all students.

Thus, there are three main reasons why AI is being intensively embedded into the educational process:

- AI helps to make the educational process more effective and convenient for both students and teachers. In Russia, some large online schools create and implement training courses with AI.

- AI increases the involvement of students in the educational process through gamification. Most training simulators use artificial intelligence to create the effective game mechanics. For example, a language school SkyEng [36] integrated AI into the educational process, it provides adaptive and personalized learning, and performs task verification in real time. AI analyses each lesson, assesses student progress, and evaluates teacher performance. Such learning system allows to change a path of student teaching.

- -implementation of AI into educational process provides automation of it. Modern educational resources can effectively function without a human: chatbots answer questions and conduct lessons. This trend is increasing every year. 


\section{VOICE USER INTERFACE}

Natural User Interface (NUI) describes interaction between a person and a computer with intuitive actions that do not require special training of users [32]. The purpose of using a user-friendly interface is to hide the complexity of a system as much as possible. Even if the user is inexperienced or requires a rather complicated interaction, it will be able to interact with the system by NUI. Examples of interfaces with NUI include interfaces based on touch, gestures, body movements (Kinect), voice, etc. Neurocomputer interfaces are expected to be created soon.

In recent years, virtual assistants with voice control have become widespread in various fields. Virtual assistants have become commercial products thanks to Apple, which introduced the Siri assistant for iPhone in 2011. Virtual assistants use a Voice User Interface (VUI), which is a humancomputer interface with voice input to control computers and devices. The VUI interface has a long history since the 1950s, when the first prototypes of devices with VUI appeared [37]. However, initially these interfaces were not highly effective, a significant breakthrough has been achieved in the last decade, thanks to the developing natural language recognition with AI. VUI have become more convenient and useful, and these technologies have gained wide popularity due to the spread of smart speakers (Amazon Echo, Google Home, Yandex.Station) and other devices with voice recognition.

There are a few significant advantages of voice input in comparison with using keyboard [37]:

- high speed of information input (faster than typing on keyboard).

- voice input can be used simultaneously with other activities (you can react without switching from the current context).

- intuitive interface.

- high level of empathy (voice messages have more empathy than text messages, interaction through voice can be more pleasant and convenient for a person).

VUI is becoming widely used as a communication for many various intelligent devices. For example, all modern smart speakers do not have a graphical display and keyboard, so you can communicate with them only by VUI. A virtual chatbot is a program that imitates the real interaction with a person. Interfaces of modern chatbots based on VUI. These types of interfaces are implemented like text chat in Facebook Messenger or Skype Instant Messaging for dialog with an intelligent device.

There are standard development tools for creation VUI. For example, a script describing the interaction between users and a script of interaction between a user and a computer have a remarkably similar structure. The only exception is that the chat-bot interface can display images and hyperlinks, while the VUI can only play sounds.

Using chat bots for learning a foreign language has the following advantages [38]:

- Gamification. Chatbots use gamification, they have built-in game mechanics to motivate students to continue learning. For example, learners receive points or other achievements for regular training or achieving a certain goal. Gamification turns learning into a hobby, it motivates users to study even during periods of rest.

- Individualization. Personal lessons with a teacher who will correct your grammatical or phonetic errors are quite expensive, and when the classes are in a group, you must wait your turn to work with the teacher. Lessons with a chat-bot removes these restrictions, you can get individual attention at any time and freely. 
- Availability. Lessons with a chat-bot can carry out at any time. The chatbot instantly answers any your questions, and you can train for several hours. This significantly increases the intensity of class and involvement in the education process.

No evaluations from the teacher and no fear of errors. For many students, the language barrier is due to an internal fear of making a mistake in dialogues. Chatbot allows to overcome this fear, remove the language barrier, help a learner to start fluently communicating.

Below, there is a description of several chatbots which designed specifically for teaching English. We compared two main categories of chatbots that can be used for self-study of English. The first category is the chat bots, which are specially designed for learning English. The second category is the chat bots for practical tasks, with them we can train English in real situations, which is an effective way of learning a foreign language.

\section{Chatbots for Language Learning}

Modern applications use AI for creating a language environment, assess the current language level, etc. Learning language with chatbots is faster than in traditional ways. With several test dialogues at beginning, the chat-bot identifies the strengths and weaknesses of student, and then configures the scripts of the dialog according to the student's language capabilities. Chatbots are adaptable, then more the learner performs the exercises and the more information collected by a chatbot, then the better it will form tasks for students. The AI allows to create individual tasks for students, make them own educational path, and then teach at a pace that is convenient for them.

Mondly [39] is a specialized program for English learning, which has two versions of the interface: an internet site and a mobile application for smartphones. The user can communicate with the Mondly by keyboard or by VOI through a microphone. The application uses a dialogue mode, when a user answering a question, he should choose the best option to answer or pronounce it aloud (the user also can type his answer in a special dialog box). If the chat-bot does not understand what the user told, it will ask him to repeat the answer. If there is a pause in the conversation, the chatbot offers several different answers for continuous of the conversation. The user can also choose how to listen of the answers in a male or female voice. Developers carry out some experiments by using a virtual reality to immerse students into the language environment with chatbots. They created Mondly VR, a special application for learning English in virtual reality glasses.

Andy [39] was designed to improve conversation practice in English. This chat-bot is positioned as a virtual teacher and you can talk to it on various topics, play language games, build vocabulary, and learn grammar rules. The user can choose a topic of discussion and get a short explanation for the corresponding grammar rule. The application supports different levels of language skills (from Beginner to Advanced). If the users have questions during the training, they can receive additional information and feedback. At the end of each topic, the user has to test himself. If there were mistakes in the test, the chatbot explains how to amend them and show the correct variant, and for unfamiliar words shows their definitions and examples of using in context. The user can talk to the chatbot on a free topic. Communication can be both written and oral by user's choice, and the chatbot corrects errors.

Virtual assistants help to practice language skills in a real-life situation. Online shops and services (travel industry, catering, etc.) use chatbots for helping customers to shop goods or book a place. Hipmunk was designed by a company that helps in a travel company. Hipmunk help to find information for travelers about hotels, flights, car rental, etc. The internet site offers a virtual assistant, and the user can get help from him through conversation on natural language. 
Conversation with the chatbot starts by saying "Hello Hipmunk", then the user can ask a question, for example, "What is the cheapest flight from Moscow to San Francisco in the first week of March?" and get a reasonable answer. The chatbot allows user to practice English questions. If Hipmunk understands your questions and can answer you, it means a sufficient level of your pronunciation.

Mona is a chatbot for helping users to make profitable purchases. Mona uses databases of large online stores and finds products that maximize the customer needs. User can ask the chatbot in a free form about what kind of good he is trying to find, what range of prices, and so on, then the chatbot will pick for user the best option. User can interact with this chat bot through a dialog. In this mode, Mona asks leading questions and provides additional information in reply to messages in a form of a menu to select an option. This is an effective way to improve your ability quickly reading and answering English questions. This type of communication allows for user to memorize words about household items, products in stores, terms related to fashion and clothing, home appliances, etc.

Android smartphones have Google Assistant as a virtual assistant that can use for daily English conversation practice. Google assistant has a natural user interface and can help to perform different tasks, for example, it can set an alarm clock at a given time by voice request. The user should be able to build several types of English sentences. If the user's pronunciation is wrong, the assistant will not execute the command. This is an effective way to improve pronunciation and train skills of making sentences without context or nonverbal clues.

Google Nest is a line of smart speakers created by Google. It has Google Assistant and allows for users to interact with VUI. By Google Nest users can receive answers from the Google search engine, launch applications, create reminders, etc. The devices enable users to implement of the Internet of things at home, the gadget can turn on and off devices, control lighting and TV, etc. Use Google Assistant for IoT, we can without Google Home device, for this you need to have a smartphone with parameters (Android 5.0+ / iOS 10.0+).

\section{Algorithm of Application Creating}

Academic English proficiency is an essential skill of a modern scientist and requires constant practice. Researchers need continuous language training for improvement their language competencies. To expand opportunities for self-development of academic English skills, we developed application for Google assistant "Academic phrase bank trivia" and "Academic trivia". The first application helps to train the vocabulary of academic English. The second helps to develop skills of building grammatically correct sentences in academic English, memorize phrases of academic vocabulary, and train the correct pronunciation.

For the developing our application, we use the Google action console, which allows to create an application for Google Assistant. In the console we step by step create an application and make some configurations using a specialising online editor. After completing all steps, we will get a fully working application that can be tested on a computer simulator or on a smartphone and publishing in Google Assistant directory. Figure 1 demonstrates the algorithm of creating the application.

The first step of the algorithm is to collect the exercises that will be used to create our application. The collected information is checking for incorrectness, if some errors are detected, the initial data are correcting, and the first step is repeated. After the final correction, the data is entered into a special Goggle Sheet template. The next step is to configure the voice interface to run the 
application and build an invocation model. Then a specialized online environment is using for building of an action. This environment is also using for building of logic, responses and intent training phrases. At next step of development, the built application can be tested in a simulator. At the next step of development, the application can be tested on a smartphone. The last step of the algorithm involves create a realize and publishing the application to Google actions directory.

When we were creating the application, we used some rules of development. Questions for the application should be brief and clear. It should be considered that the question is displayed on the smartphone screen, and there is interaction only by voice, so it is difficult for a player to remember a long question, especially in a foreign language. Therefore, questions and answers should be as short as possible. In the guide, Google recommends that the answers contain only one or two words [40].

If there are many correct answers to a question, you can specify them using the "|" separator. Any of these synonyms will be considered a valid answer. The Google guide recommends varying types of questions, which ensures dynamic learning and engagement, and questions should be as compact and clear as possible. It is recommended that the quiz be culturally and gender sensitive so that it is interesting to as many users as possible.

An action creates by the Trivia template, go to the Action console, and create a New Project. Then select the Template command in the Advanced Parameters section at the bottom of the page and specify Trivia Template in the appearing window. Then open the file from templates in Google Sheet editor. Then copy and paste the URL of the sheet in your browser and open the file in the online spreadsheet editor. 
International Journal of Computer Science, Engineering and Applications (IJCSEA) Vol.11, No.2/3/4, August 2021

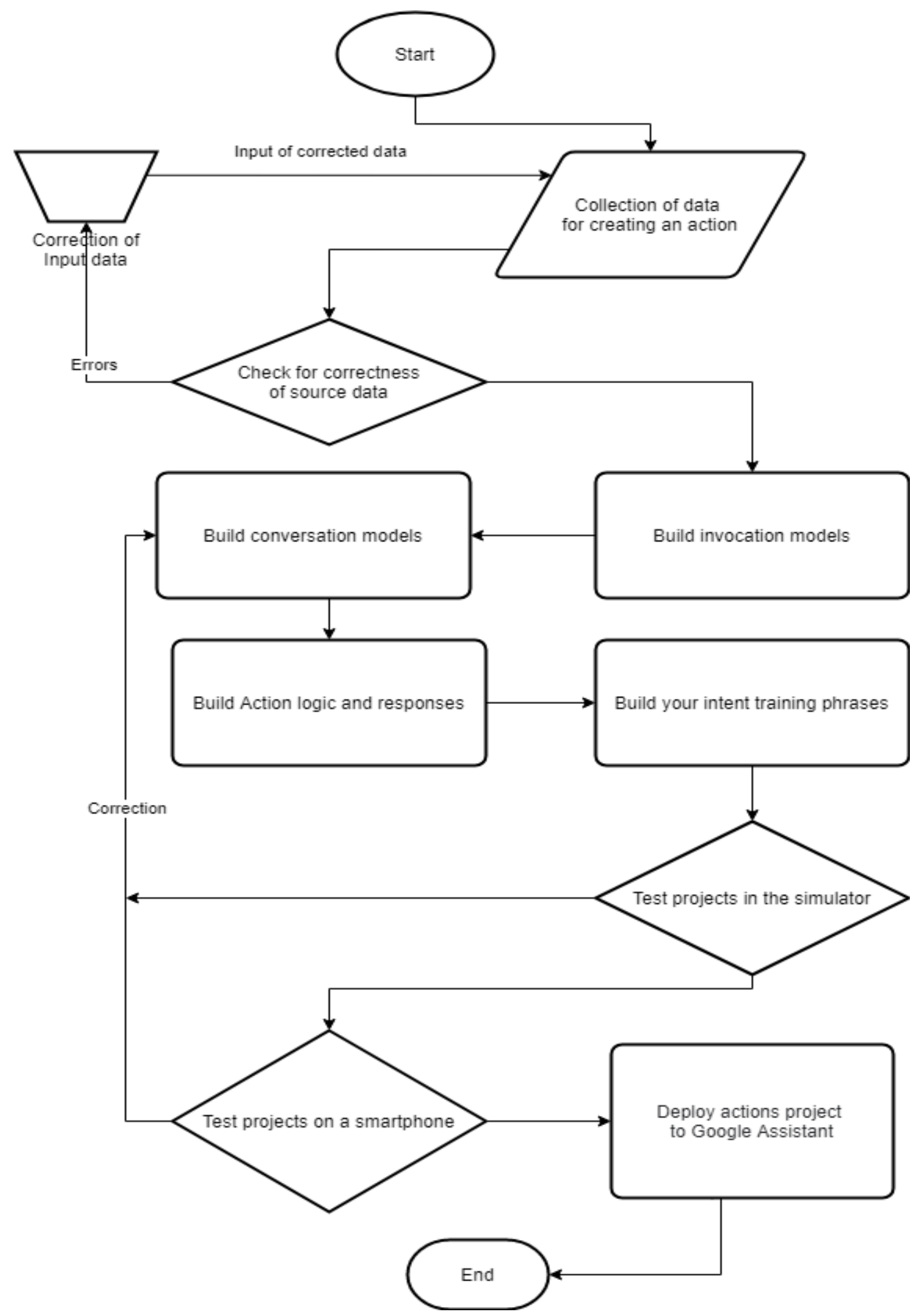

Figure 1. The algorithm of creating the application

You can fine-tune the quiz by specifying the difficulty and category for each question and create your own sound effects or speech files. You can specify difficulty levels for the questions, add a 
"Difficulty/Grade Level" column on the sheet, then specify a difficulty level or grade level for each question. You can specify up to three different difficulty levels: "Easy", "Medium" and "Hard". To separate the questions into categories, you will need to add a "Category/Topic" column and then specify a category for each question on the worksheet. You can set up to three custom categories. Before running the quiz, the user will be asked about the desired topic and the level of difficulty for the current round of questions. Additional settings and examples of using them there are in User Guide [40].

Once the action has been created, it can be tested. To do this, it is necessary to select the Test command in the top menu to test the action through the web interface. Figure 2 shows testing application in action console.

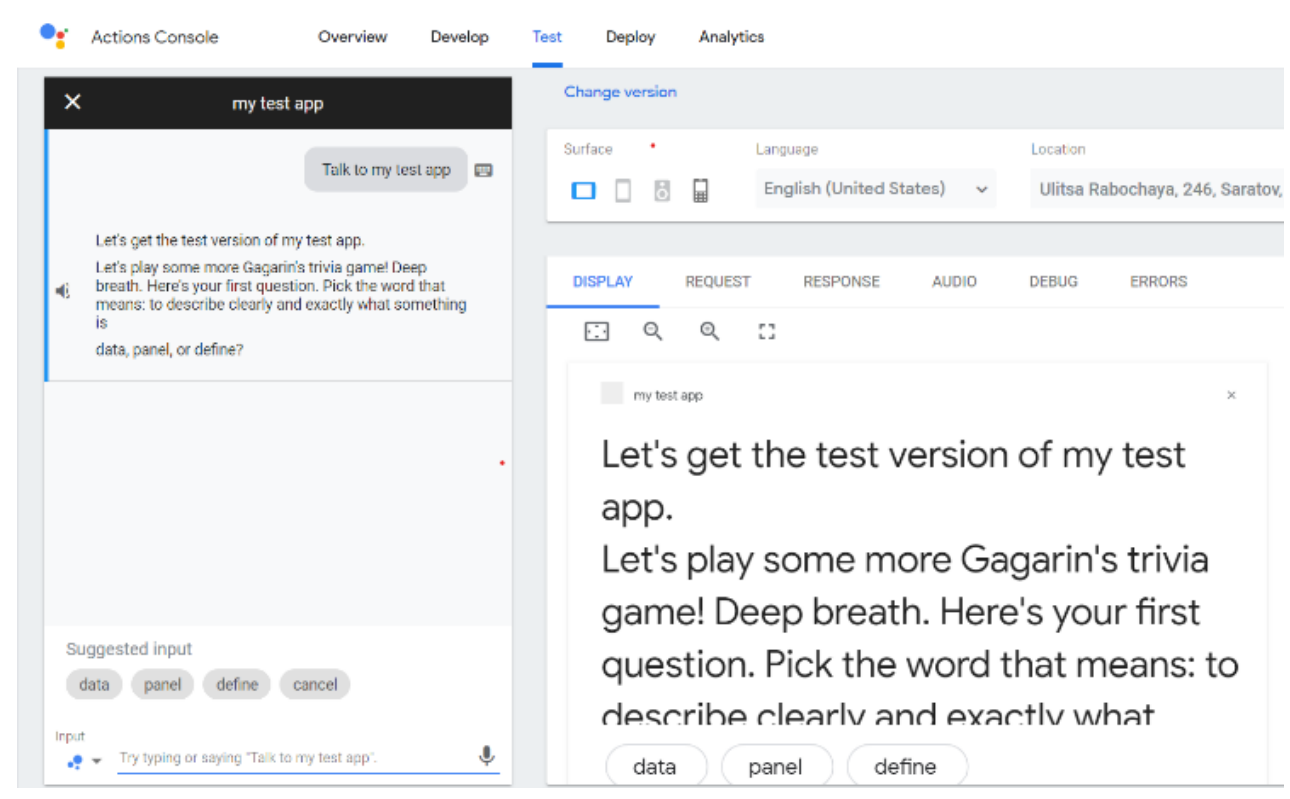

Figure 2. Test application in action console

To test the action in your smartphone, you need to run the Google Assistant and say into the microphone or enter the phrase "Talk to my test app". You can test your action through a Google Home device, the device must be connected to the same developer account. If the action supports more than one language, you should test each language separately.

\section{Voice Assistant for ACAdEMIC English Training}

A Trivia Action template was used for developing an application, in the order that was described above. This template allows you to create test quizzes, which can be run on mobile devices with Google Assistant, as well as on smart speakers with the Google Home system.

The action "Gagarin Trivia" was developed by us for vocabulary learning and training academic writing. For questions we used terms recommended by the HSE Centre for Academic Writing [41] and other quality sources [42].

To start the action, it needs to say the phrase "Play Gagarin Trivia game" to the Google assistant. Figure 3 shows the launched application, and the assistant tells you the rules of the quiz. You can choose the number of participants and the number of questions in one round. Then the first question 
will be read out and you will get three choices for answer. You must either say the answer or the answer number. If the answer is correct, the program will give the approval reaction, if not, you will get the correct answer and some explanations.

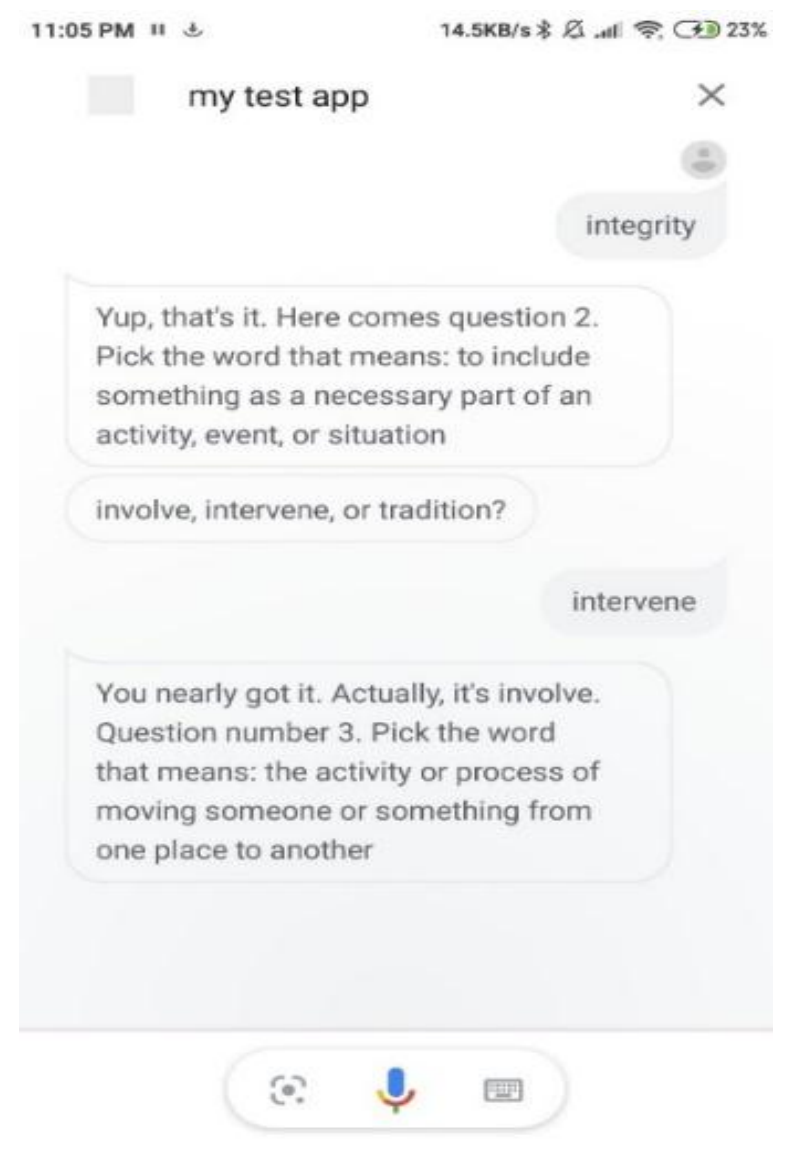

Figure 3. App view on a smartphone

If you do not understand the question, you can ask the assistant to repeat it with the command "Repeat question". If you do not know the correct answer, you can skip the question with the command "Skip question". To finish the game, you should say "Stop". At the end of the round, the assistant will summarize and tell you the number of correct answers. The application is quite fascinating. If you have the high level, you can use it even while walking, communicating with the assistant using headphones.

The second action is "Academic phrase bank Trivia" which allows to improve the knowledge of academic English. The information from English textbooks, specialized websites, and Academic phrase bank was used as a content of the application [43].

As answer to the assistant's question, it is necessary to choose the sentence closest by it meaning to the given phrase in English. As a hint, the assistant gives three options. In order for a phrase to be counted, it is not necessary to pronounce it verbatim, partial correctness is enough.

The exercise allows to improve the skill of scientific English attentive listening, and train pronunciation. In addition, the pronunciation of the templates will help them to memorize well. If you cannot pronounce the suggestions correctly, you can skip the question and proceed to the next one. 


\section{Conclusions}

A general view of the problems of education in the COVID-19 pandemic is provided by international monitoring and academic research on education in the pandemic period. In the pandemic, the mass switch to distance learning was the only way for many students to continue learning, and inequalities were exacerbated in many ways. The first manifestation of inequality is related to the technical limitations of access to the Internet and the availability of the necessary technology. Among young people there is a high proportion of those who use mobile Internet with limited traffic speed, also research shows that the computer devices also differ significantly, they depend on the income of population groups. Studies show that with the widespread introduction of the Internet, people use it differently: those with a higher level of education use it for education and career advancement, while those with a lower level of education use it for entertainment. Therefore, it is important to develop technologies to access education through mobile devices with low Internet consumption.

English proficiency enhances the quality of scientific research. Many modern scientific works published in highly ranked scientific journals are written in English. The ability to communicate confidently in English enables effective communication with other researchers. Improving language skills is a long-time process that requires considerable time and financial expenditure. The application uses the artificial intelligence of the Google platform and was designed for selfstudy of academic English and improving academic speaking skills. The application allows to study new words, to carry out the construction of grammatically correct sentences in English, to memorize templates of academic phrases. Users can train the correct pronunciation of phrases and developing skills of scientific texts listening.

\section{REFERENCES}

[1] "The covid-19 pandemic: shocks to education and policy responses." [Online]. Available: https://openknowledge.worldbank.org/bitstream/handle/10986/33696/148198.pdf. [Accessed: 10-Oct2020].

[2] "Quality Education for all during Covid-19." [Online]. Available: https://hundred.org/en/collections/quality-education-for-all-during-coronavirus. [Accessed: 24-Mar2020].

[3] "Manage teaching and learning with Classroom." [Online]. Available: https://classroom.google.com/h. [Accessed: 27-Jun-2020].

[4] "Microsoft Customer Story-STEM learning at scale: Using Microsoft Teams and AI for a more humanistic education." [Online]. Available: https://customers.microsoft.com/en-us/story/759309unsw-higher-education-azure-teams-powerbi-australia-en. [Accessed: 24-Jun-2020].

[5] T. C. Ozkaral and R. Bozyigit, "Social studies and geography teacher candidates' views on coronavirus (COVID 19) and online education process," Rev. Int. Geogr. Educ. Online, vol. 10, no. 3, pp. 467-484, 2020.

[6] W. Bao, " COVID -19 and online teaching in higher education: A case study of Peking University ," Hum. Behav. Emerg. Technol., vol. 2, no. 2, pp. 113-115, 2020.

[7] L. Mishra, T. Gupta, and A. Shree, "Online teaching-learning in higher education during lockdown period of COVID-19 pandemic," Int. J. Educ. Res. Open, vol. 1, p. 100012, 2020.

[8] M. Kerres, "Against All Odds: Education in Germany Coping with Covid-19," Postdigital Sci. Educ., vol. 2, no. 3, pp. 690-694, 2020.

[9] H. H. Pham and T. T. H. Ho, "Toward a 'new normal' with e-learning in Vietnamese higher education during the post COVID-19 pandemic," High. Educ. Res. Dev., vol. 39, no. 7, pp. 1327-1331, 2020.

[10] M. E. T. Osman, "Global impact of COVID-19 on education systems: the emergency remote teaching at Sultan Qaboos University," J. Educ. Teach., vol. 46, no. 4, pp. 463-471, 2020.

[11] T. D. Oyedotun, "Sudden change of pedagogy in education driven by COVID-19: Perspectives and evaluation from a developing country," Res. Glob., vol. 2, p. 100029, 2020. 
[12] E. M. Aucejo, J. French, M. P. Ugalde Araya, and B. Zafar, "The impact of COVID-19 on student experiences and expectations: Evidence from a survey," J. Public Econ., vol. 191, p. 104271, 2020.

[13] Z. Meleo-Erwin, B. Kollia, J. Fera, A. Jahren, and C. Basch, "Online support information for students with disabilities in colleges and universities during the COVID-19 pandemic,” Disabil. Health J., vol. 14, no. 1, p. 101013, 2021.

[14] M. N. Artemenkov and E. E. Suhova, "Transformation of school graduates' educational strategies in the context of coronavirus COVID-19: regional dimension," Reg. nye Issled., pp. 111-120, 2020.

[15] S. Rashid and S. S. Yadav, "Impact of Covid-19 Pandemic on Higher Education and Research," Indian J. Hum. Dev., vol. 14, no. 2, pp. 340-343, 2020.

[16] A. El Masri and E. Sabzalieva, "Dealing with disruption, rethinking recovery: Policy responses to the COVID-19 pandemic in higher education," Policy Des. Pract., vol. 3, no. 3, pp. 312-333, 2020.

[17] J. D. Hansen and J. Reich, "Democratizing education? Examining access and usage patterns in massive open online courses,” Science (80-. )., vol. 350, no. 6265, pp. 1245-1248, 2015.

[18] E. Hargittai and A. Hinnant, "Digital inequality: Differences in young adults' use of the Internet," Communic. Res., vol. 35, no. 5, pp. 602-621, 2008.

[19] S. Bennett, K. Maton, and L. Kervin, "The 'digital natives' debate: A critical review of the evidence," Br. J. Educ. Technol., vol. 39, no. 5, pp. 775-786, 2008.

[20] P. A. Kirschner and J. J. G. van Merriënboer, "Do Learners Really Know Best? Urban Legends in Education," Educ. Psychol., vol. 48, no. 3, pp. 169-183, 2013.

[21] L. Y. Muilenburg and Z. L. Berge, "Students Barriers to Online Learning: A factor analytic study," Distance Educ., vol. 26, no. 1, pp. 29-48, 2005.

[22] C. Milligan and A. Littlejohn, "Supporting professional learning in a massive open online course," Int. Rev. Res. Open Distance Learn., vol. 15, no. 5, pp. 197-213, 2014.

[23] A. R. Artino and J. M. Stephens, "Academic motivation and self-regulation: A comparative analysis of undergraduate and graduate students learning online," Internet High. Educ., vol. 12, no. 3-4, pp. 146$151,2009$.

[24] K. M. Soria and B. Horgos, "Factors associated with college students' mental health during the COVID19 pandemic,” J. Coll. Stud. Dev., vol. 62, no. 2, pp. 236-242, 2021.

[25] N. W. Buddhima and S. Keerthiwansha, "Artificial Intelligence Education (AIEd) in English as a Second Language (ESL) Classroom in Sri Lanka,” Int. J. Conceptions Comput. Inf. Technol., vol. 6, no. 1, pp. 2345-9808, 2018.

[26] S. Popenici and S. Kerr, "Exploring the impact of artificial intelligence on teaching and learning in higher education,” Res. Pract. Technol. Enhanc. Learn., vol. 12, no. 1, p. 22, Dec. 2017.

[27] T. Karsenti, "Artificial intelligence in education: The urgent need to prepare teachers for tomorrow's schools," Form. Prof., vol. 27, no. 1, p. 105, 2019.

[28] M. J. Timms, "Letting Artificial Intelligence in Education out of the Box: Educational Cobots and Smart Classrooms,” Int. J. Artif. Intell. Educ., vol. 26, no. 2, pp. 701-712, 2016.

[29] A. Łuczak, "Using Memrise in Legal English Teaching," Stud. Logic, Gramm. Rhetor., vol. 49, no. 1, pp. 141-152, Mar. 2017.

[30] G. D. Boca, "The Impact of IT on Knowledge Feedback to Education Design," Procedia - Soc. Behav. Sci., vol. 83, pp. 856-861, Jul. 2013.

[31] P. B. Sing, M. A. Embi, and H. Hashim, "Ask the Assistant: Using Google Assistant in Classroom Reading Comprehension Activities,” Int. J. New Technol. Res., vol. 5, no. 7, pp. 39-43, 2019.

[32] Berdasco, López, Diaz, Quesada, and Guerrero, "User Experience Comparison of Intelligent Personal Assistants: Alexa, Google Assistant, Siri and Cortana," Proceedings, vol. 31, no. 1, p. 51, Nov. 2019.

[33] O. Metatla, A. Oldfield, T. Ahmed, A. Vafeas, and S. Miglani, "Voice User Interfaces in Schools," in Proceedings of the 2019 CHI Conference on Human Factors in Computing Systems - CHI '19, 2019, pp. $1-15$.

[34] O. A. Pyrnova and R. S. Zaripova, “Technologies of artificial intelligence in education,” Russ. J. Educ. Psychol., vol. 10, no. 3, pp. 41-50, Jun. 2019.

[35] "How software that learns as it teaches is upgrading Brazilian education." [Online]. Available: https://www.theguardian.com/technology/2016/jan/10/geekie-educational-software-brazil-machinelearning. [Accessed: 24-Feb-2020].

[36] "School of English - individual learning English at Skyeng School." [Online]. Available: https://skyeng.ru/. [Accessed: 24-Feb-2020].

[37] C. Pearl, Designing Voice User Interfaces by Cathy Pearl Chapter 1 . Introduction A Brief History of VUIs. O’Reilly Media, Inc., 2016. 
[38] G. Terzopoulos and M. Satratzemi, "Voice assistants and artificial intelligence in education,” ACM Int. Conf. Proceeding Ser., 2019.

[39] "Mondly - Learn languages online for free." [Online]. Available: https://mondly.com/. [Accessed: 25Feb-2020].

[40] "Create a Trivia Action using templates | Actions on Google Templates." [Online]. Available: https://developers.google.com/assistant/templates/trivia. [Accessed: 24-Feb-2020].

[41] "HSE - UniversityAcademic Development - Academic Writing Centre - Podcasts." [Online]. Available: https://academics.hse.ru/awc/podcasts. [Accessed: 25-Feb-2020].

[42] "Glossary of terms for academic writing - Wiki - innsida.ntnu.no." [Online]. Available: https://innsida.ntnu.no/wiki/-/wiki/English/Glossary+of+terms+for+academic+writing. [Accessed: 25-Feb-2020].

[43] "Home Page - Academic Phrasebank." [Online]. Available: http://www.phrasebank.manchester.ac.uk/. [Accessed: 12-Jun-2020].

\section{AUTHOR}

Received degree of Doctor of Economic Sciences in Logistics from Saint Petersburg state university of Economics, Russia in 2011. He has an industrial experience of 10 years in programming, and an academic experience of over 20 years in Yuri Gagarin State Technical University of Saratov, with research in versatile fields of transport, logistics, and computer science.

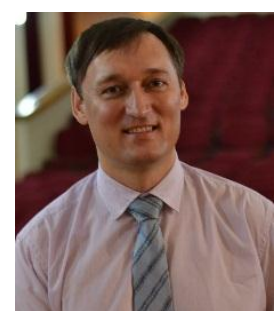

